\title{
Research on the Construction of Chinese Hotel Experi- ential Marketing Model Under the Background of AI
}

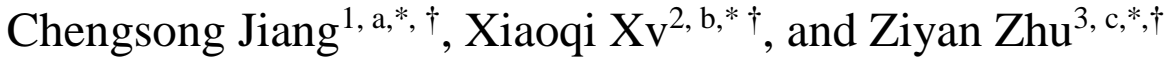 \\ ${ }^{1}$ Arizona State University, Economics, Heng Da Ming Du, Shi You Road, Yuzhongqu Dist, Chongqing, China; \\ ${ }^{2}$ Zhengzhou University, Hotel Management, No. 100 Kexue Avenue Fengyang Street High tech Zone Zhengzhou City, \\ Henan Province, China; \\ ${ }^{3}$ University of California, Davis. Statistic and Communication, 10F, No18, Jin YinhuRoad, DongXIHU, Wuhan, \\ Hubei, China. \\ * Corresponding author: ${ }^{a}$ Cjiang40@asu.edu, ${ }^{b} X i a o q i x v \_j o y @ s t u . z z u . e d u . c n,{ }^{c} v i v z h u @ u c d a v i s . e d u$. \\ These authors contributed equally.
}

\begin{abstract}
As the hotel industry wants to occupy a certain market in the fierce competition, it is necessary to implement an experiential marketing strategy to provide corresponding products and services to enhance customer experience and realize customer experience value. In order to stand out in the fierce competition of the market environment, it is necessary to use a clear marketing mode and pay attention to the differentiated marketing focus and target at the same time as centralized marketing. This paper takes some kinds of AI hotels as the research object. Because of the increasingly fierce competition in the hotel industry, this paper makes a comparative analysis of the implementation of experiential marketing. Based on the problems existing in these hotels, combined with the smart model, this paper constructs the experiential marketing mode. It is hoped that under the current market competition environment, the developed experiential marketing mode can promote the expansion of hotel business, and provide certain guidance for hotels to win more market share.
\end{abstract}

Keywords: Chinese hotel, Experiential marking, Model construction.

\section{INTRODUCTION}

With the all-around well-off society, tourism resources are increasingly rising. In 2019, the number of domestic tourists in China increased by 8.40 percent year-on-year to 6.06 billion. The total number of limitedservice hotels in China had reached 42,419 , up $42.54 \%$ yearly [1]. China's hotel industry is not only the tertiary industry but also the service industry. The hotel industry is intensive, and its development is of great significance to solve the employment problem in China. Simultaneously, the traditional model of high input and low output, more international groups to seize the Chinese market and other factors, also put forward new challenges to China's hotel industry's future development.

In a word, the provision of hotel products and services has simultaneity. When consumers purchase hotel products, they virtually consume the services provided by the hotel. What customers get is not only the short-term right to use the hotel rooms, but also a series of services provided by the hotel, including warm or business or simple hotel atmosphere, and even Turndown Service [2]. In other words, the real profit that the hotel really attracts customers is the wonderful "experience" that the hotel leaves customers. Therefore, we think that experiential marketing is very important for hotel management and development. Meanwhile, combined with the network data, we can find that the application trend of $\mathrm{AI}$ in the service industry is gradually increasing. The utilization rate of $\mathrm{AI}$ reaches $47 \%-56 \%$ in customer attraction, risk management, production, and profit optimization, etc. And nearly $21 \%-26 \%$ of the unused links are introducing $\mathrm{AI}$, and even $15 \%-21 \%$ of the artificial links will include $\mathrm{AI}$ in the production within two years. Its popularization has gradually become a general trend [3]. Based on the "experience" characteristic of hotel products and the current form of science and technology, the author will combine the S.M.A.R.T and SEMs model to mine the problems existing in the experience marketing of hotel internal customers and give further improvement suggestions. 
Through these two articles, we have discovered the current status of the use of experiential marketing, but one is to abandon the old experiential marketing and develop immersive experiential marketing; one does not improve but develops new strategies to adapt to this experiential marketing. Hongjia Sun found that the overall performance of my country's hotel industry has declined. Some hotels have begun to try to use advanced technology to improve efficiency. They are creating immersive experiential marketing through the application of the $5 \mathrm{G}+\mathrm{AI}+$ regional chain in the hotel. For experiential marketing, it has several unique characteristics compared to traditional marketing. First, individuality refers to allowing every different individual to actively participate in marketing. Also, the plan and design of the event should reflect individuality. Second, intangibility refers to the specific intangibility that can make consumers feel unforgettable and specific feelings during the entire experiential marketing process. Third, continuity means that after the consumer's feelings get the corresponding experience, the specific feeling will not disappear immediately. If consumers feel comfortable or satisfied during the entire experience, then they will have high loyalty to the corresponding product. Fourth, interactivity means that consumer participation is necessary. Only when consumers participate can they form a good mode of communication and interaction with the company so that experiential marketing allows consumers to have sensory stimulation in their activities [4]. Hongxiu Zhou found that the consumption of hotel products under the background of the experience economy is more personalized. These distinctive hotel service types can improve the brand power and competitiveness of the hotel itself and attract a large number of tourists to come for tourism consumption. In the context of the experience economy era, hotels should focus on experience marketing. That means visitors can get great spiritual satisfaction while staying through the simple design of some scenes. Reverse marketing means customer needs as the purpose. Internal marketing means hotels fully consider the personal factors and external factors of the employees. Culture means using cultural power to realize a comprehensive exploration of the hotel. And personalization and emotional marketing let guests obtain certain emotional pleasure and satisfaction [5].

Through literature review, we can find that most of the literature and hotel-specific cases are about using experiential marketing to meet the hotel operating problems. Most of them discuss how to use models or concepts, but few literatures discuss what should be paid attention to in the process of using them. And this blank point is often easy to cause problems in the use of the hotel. Therefore, we apply S.M.A.R.T. models to analyze the problems and solutions of hotel experience marketing under AI background. Currently, there are few standardized experience marketing models, so our idea is to set a standard for the use of experience marketing, improve and upgrade experience marketing to a certain extent to better adapt to the era of AI.

\section{METHODOLOGY}

We will use several methods to analyze methodology, such as literature research method, case study method, model method.

\subsection{Literature research method}

The literature research method refers to the concept of analyzing and re-categorizing relevant literature based on existing theories, facts, and needs. Through seeing the two articles from Hongjia Sun and Hongxiu Zhou, we find the research gaps in knowing which topic we gonna research. Through seeing some books, we know several models about experiential marketing such as SEMs model, SMART model, and Test model to let us know the basis of theoretical Research. Through seeing some professional reports, we know the hotel marketing needs to change. They need to change their marketing methods.

\subsection{Case analysis method}

The case analysis method refers to combining literature to analyze a single object and get the general and universal law of things. In this paper, we will combine the case analysis method by analyzing the actual hotel experience marketing situation by comparing the experiential marketing situation of Yaduo Hotel and Hupu basketball hotel, combined with a smart model to discuss the standard of hotel experience marketing. Our conclusion is nested and compared with the actual case to make the conclusion normative, universal, and practical.

\subsection{Model analysis method}

The SMART principle favors employees more clearly and efficiently. The future managers for employee performance appraisal provide the evaluation target and evaluation standard, making the evaluation more scientific, standardized, and can guarantee justice and fairness. We will use this model to bring the superiors and subordinates of the hotel staff into discussion together. On the mission of the hotel, we base the overall goals of the hotel for a certain period, and from there, assign the responsibilities and goals to the superiors and subordinates. After that, we will use this model to analyze hotels' advantages and disadvantages in the AI industry. 


\section{RESULT}

\subsection{The current situation of experiential marketing of AI hotels in China}

In March 2015, DoubleTree by Hilton Moscow installed an HDL intelligent lighting control system for its restaurants. According to the preset lighting scene, managers can control the lighting equipment through the control panel and adjust the lighting of the dining environment in the restaurant [6].

In April 2019, at the Shanghai International Hotel Engineering Design and Supplies Expo, HDL launched the first "face unlock" innovative hotel solution. To realize face recognition and match the entire room control experience, HDL has developed a new app-level innovative hotel control interface: HotelUI [6].

Flying Pig Travel, a subsidiary of Alibaba Group, has built a fully "artificial intelligence hotel" in Hangzhou, adopting an intelligent service system. Guests can control the curtains, lamps and televisions, and other equipment through brilliant voice. Guests can also call the hotel services directly through the "Tmall Wizard," such as checking the breakfast time, calling the hotel car, and hotel room service.

With the development of artificial intelligence, intelligent technology has gradually attracted attention and has been applied in the hotel industry. Although it is only in the initial stage at present, the rise of the concept of "smart hotel" is enough to attract the industry's attention, especially in the context of the high acceptance of new technology in China.

\subsection{Problems in China's AI hotel experiential marketing}

Let us take a Hilton Hotel and the Alibaba Hotel in Hangzhou as an example. These are two different types of hotels. One is a traditional hotel, and the other one is basically using all the AI systems building the hotel. The Hilton Hotel also uses some basic AI systems. For instance, when people go into the room of the hotel, the light will be turned on by themselves through the voice. But other facilities in the room are not AI systems. However, Alibaba Hotel in Hangzhou is really different. It is a new model for a hotel. It uses AI technology throughout the process to save you a lot of time. People can through their face to enter the room of the hotel. When people get hungry or wang to know the hotel's surroundings, the room can also help them find it. Moreover, in the Hilton Hotel, people need to carry huge luggage to their room during the peak flow. The Alibaba Hotel can save this problem. They can directly help you transport your luggage to your corresponding room. Therefore, AI Hotel brings us a lot of conveniences.
Through analyzing two specific examples of the hotel, we list two main problems in China's AI hotel experiential marketing.

\subsubsection{Upfront costs increase}

The establishment of a smart hotel system requires the construction of various engineering systems connected to the Internet of Things, such as room control systems, building control systems, intelligent parking management systems, wireless communication systems, and food delivery robots. At the same time, these systems also need to maintain long-term maintenance. The security system also needs to be perfected regularly because intelligent services are bound to involve customers' privacy, such as personal information such as facial recognition or fingerprints. Therefore, it will significantly increase the construction and operation costs of the hotel.

\subsubsection{Rising unemployment rate}

As AI booms, there is no doubt that AI will replace more and more jobs. Professors Michael Osborne and Carl Frey from the University of Cambridge published a report that analyzed the probability of 365 occupations being made obsolete by artificial intelligence in the future, using an extensive data computing system, the BBC reported. The most challenging jobs to be replaced are hoteliers $(0.4$ percent), teachers $(0.4$ percent $)$, psychologists $(0.7$ percent), and public relations (1.4 percent), apparently demanding skills in networking, negotiation, and the art of people.[7] Jobs that require a lot of interaction to master people's emotions and psychology are very unlikely to be replaced by artificial intelligence. In contrast, security guards, customer service staff, receptionists, telephone operators, accountants, and counter clerks are far more dangerous. Waiters and waitresses have a 98.5 percent chance of being replaced, and these positions are also the most crowded in traditional hotels. In the future, artificial intelligence will replace many simple and repetitive jobs, not only those in hotels but also a large number of low-skilled jobs in banking, securities, insurance, and accounting in the financial industry.

\section{DISCUSSION}

\subsection{Key points of experiential marketing}

Through the analysis and discussion of the above problems, this part will combine part of the SMART model with building the hotel experiential marketing use mode and try to combine with the Balanced Scorecard to explore the establishment of hotel experiential marketing use performance evaluation index system. Hope to build the use mode for hotel experiential marketing to improve its standardization, economy, and efficiency. 


\subsubsection{Specific : Hotel experience marketing must be specific}

The use of experiential marketing must be purposeful, and hotels must understand what they want to get through experiential marketing [8]. For example, the appearance of Fashion AI Concept store is for the convenience of both buyers and sellers - not only to let customers easily and intuitively experience clothes but also to reduce the cost of store fitting room and the uncertain damage of clothes when they are tried on. Of course, the result of this effort is to further attract consumers to buy while reducing costs, and the most direct purpose is to make profits. In this case, the purpose of experiential marketing is profit. For another example, the worldfamous Yaduo Hotel, as a relatively mature old brand hotel, simple sales cannot meet the needs of its further expansion. Therefore, it began to focus on "service and lifestyle brand for the new middle class". In other words, the way of layout expansion at home and abroad that Yaduo is committed to being not only room sales but also a huge user experience social circle. Its experience marketing brings consumers' recognition of Yaduo's lifestyle [9]. Therefore, the direct purpose of Yaduo's experiential marketing is consumer identity. In a word, we should clarify our users' purpose, whether it is for profit, cultural communication, or other purposes, and take this as the basis.

\subsubsection{Measurable: The use of hotel experience marketing should be measurable}

The use of hotel experiential marketing should be quantifiable. At the same time, this measurability is also phased. Not only can the results be measured, but every stage. In short, if the use effect cannot be measured, how can hotels know whether their use is effective or ineffective? Therefore, before using, hotels need to know whether the results they want can be quantified. For example, if they want to enhance the sales of hotel rooms, the quantitative index is the number of hotel rooms sold. Besides, why should measurable be divided into stages? Because the purpose of quantification is to ensure the efficiency of use. The phased quantification means that users can evaluate their use effect in each stage to further improve the later stage and finally achieve their own purpose.

\subsubsection{Attainable : The use of hotel experience marketing should be realizable}

If the hotel's experiential marketing cannot be put into use, then this kind of experiential marketing means nothing. For example, if an economy hotel with an average room price of 150 yuan carries out experiential marketing of senior executive suites. Both the hotel's own holdings of senior executive suites and the consumption level of its customers cannot meet this demand. Therefore, experiential marketing must adapt to the hotel's grade and consumption level to ensure its realizability.

\subsubsection{Time-based : Hotel experiential marketing needs to pay attention to timeliness}

Just as delicious food has a shelf life, effective experiential marketing should also pay attention to time. And time is not the use period of experience marketing, but its application period. With the development of science and technology, consumers' perception of service is constantly changing. People thought that hotel products were just a bed in the past, but now people think that hotel products also include services. Therefore, the use of experiential marketing is not achieved overnight but should be improved with the change of KPI day by day.

These are the requirements of experiential marketing. Also, all of them are not separated but connected. For example, the timeliness of using experiential marketing needs to be based on the stage results in the use process to determine whether it is applicable in the later development, and this result is based on measurable.

\subsection{Experiential marketing mode system}

Through seeing those problems of the hotel, having a standard of experiential marketing will be a good way to improve. By integrating the above four aspects and three dimensions of the balanced scorecard [10], the performance evaluation system of hotel experiential marketing is established by using financial and nonfinancial indicators, and is shown in Figure 1.

Table 1. Hotel experiential marketing application model system.

\begin{tabular}{|c|c|c|c|}
\hline $\begin{array}{c}\text { Evaluation dimension of } \\
\text { Balanced Scorecard }\end{array}$ & $\begin{array}{c}\text { Hotel experiential } \\
\text { marketing use } \\
\text { performance } \\
\text { appraisal content }\end{array}$ & evaluating indicator & remarks \\
\hline Customer & Specific & $\begin{array}{c}\text { Integrity of marketing } \\
\text { design }\end{array}$ & $\begin{array}{c}\text { The integrity of marketing } \\
\text { design should include: time }\end{array}$ \\
\hline
\end{tabular}




\begin{tabular}{|c|c|c|c|}
\hline & & & $\begin{array}{l}\text { range, } \mathrm{KPI} \text {, method, person } \\
\text { in charge, etc }\end{array}$ \\
\hline & & Customer satisfaction & $\begin{array}{l}\text { By inviting customers to } \\
\text { score, it is advisable to } \\
\text { know whether the } \\
\text { marketing target has been } \\
\text { achieved or not, and } 80 \% \text { is } \\
\text { considered as desirable }\end{array}$ \\
\hline & \multirow[b]{2}{*}{ Measurable } & $\begin{array}{c}\text { Customer Attractive } \\
\text { Volume }\end{array}$ & / \\
\hline & & $\begin{array}{l}\text { Marketing conversion } \\
\text { rate }\end{array}$ & $\begin{array}{l}\text { The ratio of the cost of } \\
\text { human and material } \\
\text { resources invested in } \\
\text { marketing to the final } \\
\text { achievement (which can be } \\
\text { the revenue and the } \\
\text { customer group attracted) }\end{array}$ \\
\hline & \multirow[b]{2}{*}{ Attainable } & Plan completion rate & l \\
\hline & & $\begin{array}{c}\text { Material } \\
\text { completeness }\end{array}$ & / \\
\hline \multirow[b]{2}{*}{ Financial capability } & \multirow[b]{2}{*}{ Attainable } & Cost expense ratio & / \\
\hline & & $\begin{array}{l}\text { Completion rate of } \\
\text { fund plan }\end{array}$ & l \\
\hline \multirow{4}{*}{ Operation flow } & Specific & $\begin{array}{l}\text { Experience quality } \\
\text { assurance }\end{array}$ & $\begin{array}{l}\text { By inviting customers to } \\
\text { score, we can know } \\
\text { whether the sense of } \\
\text { experience has reached } \\
80 \%\end{array}$ \\
\hline & Measurable & $\begin{array}{c}\text { Qualified rate of each } \\
\text { service }\end{array}$ & $\begin{array}{l}\text { Hotels need to set service } \\
\text { requirements standards in } \\
\text { advance (for example, } \\
\text { several actions need to be } \\
\text { completed for a service), } \\
\text { and judge the degree of } \\
\text { eligibility on this basis }\end{array}$ \\
\hline & \multirow{2}{*}{ Time-based } & $\begin{array}{l}\text { General schedule of } \\
\text { marketing service }\end{array}$ & l \\
\hline & & $\begin{array}{l}\text { General schedule of } \\
\text { marketing service }\end{array}$ & l \\
\hline
\end{tabular}

\section{CONCLUSION}

\subsection{Summary}

To sum up, we first list two examples of the traditional and AI system's hotel to analyze the situation of China's hotel. Then, we post several examples for AI hotel in China, such as DoubleTree by Hilton Moscow installed an HDL intelligent lighting control system for its restaurants in 2015. HDL has developed a new app-level innovative hotel control interface: Hotel UI in 2019, Flying Pig Travel, adopting an intelligent service system.
Then, we list two problems of China's AI hotel experience marketing. First, upfront costs are increasing because people need to pay more money for the AI system, and the unemployment rate is rising because the AI system can replace many jobs of the hotel like waiters. Moreover, we use part of the SMART model to build the hotel experiential marketing and combine it with the Balanced Scorecard to explore the establishment of the hotel experiential marketing use performance evaluation index system. 


\subsection{Limitations}

This study has potential limitations. We used some online materials to analyze our projects but did not use the investigation and research method to confirm our projects. However, in future research, we will use the survey method to collect first-hand data for more accurate analysis.

\section{REFERENCES}

[1] Zhiyan Consulting Group , Report on Market Potential Analysis and Investment Direction of China Single Hotel Industry (2019-2025)

[2] Fan Xiaoqing. Application of experiential marketing in automobile brand communication $[\mathrm{J}]$. Management and technology of small and medium sized enterprises (first ten issues), 2021 (01): 156157

[3] CFT50, Research Fintechs Research, Statistics on AI Functional Applications in the Service Industry

[4] Hongjia Sun, Research on hotel experience marketing strategy and its application in the era of $5 \mathrm{G}+\mathrm{AI}+$ blockchain (2019)

[5] Hongxiu Zhou, An Analysis of Hotel Experience Marketing Strategies under the Background of Experience Economy (2018)

[6] 2019 China smart hotel market analysis report industry status and development trend analysis

[7] Yidaoboshi, Will artificial intelligence lead to mass unemployment

[8] Li Li. Focus on experiential marketing [J]. Hubei pictorial (Hubei Tourism), 2021 (01): 92-93

[9] Yvyang Zhu, Research on the optimization of hotel experience marketing strategy[D], Shanghai Normal University,2019

[10] Yang Yuanjing. Research on performance evaluation index of PPP project of municipal road engineering $[\mathrm{J}]$. Accounting of township enterprises in China, 2021 (04): 72-73 